\title{
Percepções e perspectivas discentes nos cursos de pós-graduação em Escrita Criativa da PUCRS
}

\section{Student/alumni perceptions and perspectives in the postgraduate studies Creative Writing courses at PUCRS}

\author{
LUIZ ANTONIO DE ASSIS BRASIL \\ BERNARDO BUENO \\ Pontifícia Universidade Católica do Rio Grande do Sul, Porto Alegre, RS, Brasil \\ GABRIELA SILVA \\ Universidade Regional Integrada do Alto Uruguai - URI, Erechim, RS, Brasil \\ MOEMA VILELA PEREIRA \\ MARÍA ELENA MORÁN ATENCIO \\ GABRIEL EDUARDO BORTULINI \\ MARCELO MALDONADO CRUZ \\ TIAGO DANTAS GERMANO \\ DANIEL FERNANDO GRUBER \\ LARA MARIA LUFT \\ FELIPE KARPINSKI MASSARO \\ LAILA RIBEIRO SILVA \\ Pontifícia Universidade Católica do Rio Grande do Sul, Porto Alegre, RS, Brasil
}

\begin{abstract}
Resumo: Este artigo se propõe a analisar os dados parciais obtidos pelo grupo de pesquisa Escrita Criativa na Academia: a formação do escritor, que desenvolve, desde 2015, uma pesquisa cujo objetivo geral é analisar a estrutura curricular e as condições de ensino oferecidas pelos cursos de mestrado e doutorado voltados para a formação do escritor, do pesquisador e do docente na área de Escrita Criativa da PUCRS. Pretende-se aqui discutir quais são as percepções dos alunos e egressos do programa de pós-graduação em Escrita Criativa sobre os aspectos mais importantes de sua educação e seus objetivos profissionais na área.
\end{abstract}

Palavras-chave: Escrita criativa; Ensino superior; Pós-graduação; Brasil

\begin{abstract}
This article aims to analyze the partial data obtained by the Creative Writing in Academia - the writer's education research group at the Pontifical Catholic University of Rio Grande do Sul (PUCRS) in Brazil. This research, developed since 2015, has as main objective the analysis of Master and PhD-level Creative Writing courses at PUCRS, focusing on study conditions and student/alumni perceptions about their education, its most important aspects, as well as their professional aspirations in Creative Writing.
\end{abstract}

Keywords: Creative writing; Higher education; Graduate studies; Brazil

\section{Introdução}

A Pontifícia Universidade Católica do Rio Grande do Sul possui consolidada expertise na área da Escrita Criativa. Desde 1985 mantém sua Oficina de Criação Literária, a qual se notabiliza como a mais antiga em atuação ininterrupta no Brasil, atraindo alunos de todos os quadrantes do País. Mantém até hoje o seu caráter extensionista, ligada à Educação Continuada da mesma Universidade, recebendo alunos cujo perfil, presentemente, é representado por jovens universitários ou jovens profissionais das mais diversas áreas, embora prevaleçam as Humanidades. Pela Oficina já passaram mais de 700 alunos, e vários destes vêm obtendo relevantes prêmios e indicações de certames nacionais e internacionais, como o Portugal Telecom, São Paulo e Jabuti, e têm publicado pelas mais importantes editoras nacionais e internacionais. 
Com base nesse conhecimento acumulado, em 2009 foi possível avançar para a criação de uma linha de pesquisa específica, incluída na Área de Concentração da Teoria da Literatura do Programa de Pós-Graduação em Letras, denominada Margens da Literatura: produção e recepção, que propiciava a emissão do diploma de mestre ou doutor em Teoria da Literatura com ênfase na Escrita Criativa. Nessa linha, foram defendidas e apresentadas duas teses de doutorado e dezesseis dissertações de mestrado.

Em 2012 foi dado um grande passo, instituindose, em caráter pioneiro em âmbito nacional, a Área de Concentração em Escrita Criativa, com cursos de pósgraduação stricto sensu. A receptividade foi acima da esperada, com número de candidatos muito maior do que as vagas disponíveis. A Área conta, atualmente, com oito professores em regime de tempo integral. Formou três doutores e quatorze mestres. Em 2016, havia 22 alunos de mestrado e 19 de doutorado, provenientes de dez estados e do Distrito Federal, das regiões Sul, Sudeste, CentroOeste e Nordeste, e de países da Europa e América Latina.

Com caráter interdisciplinar, a Área possui duas linhas de pesquisa, a saber: Fundamentos Linguístico-Literários da Linguagem, comum também às áreas de Linguística e Teoria Literária, e Leitura, Criação e Sistema Literário, que investiga a gênese de textos literários e não-literários, sua relação com outras linguagens, a inclusão do escritor no sistema literário - apoiada em teorias críticas da literatura e em documentos de escritores sobre o processo de criação, com o foco voltado à criação literária e seus fundamentos estéticos, à crítica genética, às relações entre literatura e outras mídias, produção de roteiros teatrais e fílmicos e criação de textos não literários. $\mathrm{O}$ acervo do DELFOS - Espaço de Documentação e Memória Cultural - estão à disposição para investigação e aulas in loco sobre o processo criativo dos escritores através do manuseio e da análise dos manuscritos, correspondências, fotografias e anotações registradas em livros e outros materiais que integram o Espaço.

Se a Oficina Literária mantém seu caráter algo informal, a Área de Concentração regulariza-se no Programa com carga específica de disciplinas e outras ações acadêmicas, com publicações, grupos de pesquisa e grupos de estudo. A maioria dos alunos está contemplada com bolsas parciais ou integrais (via CAPES e CNPq).

Analisando a estrutura da pós-graduação em Escrita Criativa na PUCRS, constatamos um alinhamento, de maneira geral, com cursos semelhantes oferecidos em universidades no exterior, como, por exemplo, a Universidade de East Anglia, no Reino Unido, e a Universidade de Columbia, nos Estados Unidos. Entretanto, em termos mais específicos, os cursos diferenciam-se em alguns aspectos.

A Universidade de East Anglia, por exemplo, oferece o curso de mestrado em Escrita Criativa mais antigo do
Reino Unido - desde a década de 1970. Com um ano de duração, o curso é mais breve que o da PUCRS e tem uma abordagem mais prática: os alunos frequentam oficinas literárias (nas quais professores e colegas comentam textos lidos em aula) e algumas disciplinas da pós-graduação, mas com uma carga horária consideravelmente mais concisa. $\mathrm{O}$ curso de $\mathrm{PhD}$ (doutorado), por outro lado, tem três anos de duração e uma exigência maior nos aspectos teóricos, tanto que o título do curso é Creative and Critical Writing (Escrita Criativa e Crítica). Na Universidade de Columbia, nos Estados Unidos, por outro lado, o departamento de escrita é associado ao departamento de Artes, e não ao de Inglês, como é mais comum. O mestrado é, também, considerado o grau final, e não há cursos de doutorado em Escrita Criativa nessa universidade.

Embora a juventude das ações de pós-graduação da PUCRS na Escrita Criativa, já é possível notar alguns indícios que surgem na prática de sala de aula, referentes a dúvidas de discentes e docentes. Com o intuito de compreender melhor essas questões, com dados que possam dar base para o aperfeiçoamento dessa Área de Concentração incipiente na universidade brasileira, o grupo de pesquisa Escrita Criativa na Academia: a formação do escritor desenvolve, desde 2015, uma pesquisa cujo objetivo geral é analisar a estrutura curricular e as condições de ensino oferecidas pelos cursos de mestrado e doutorado para a formação do escritor, do pesquisador e do docente na área de Escrita Criativa. Busca-se identificar e caracterizar quais são as competências e habilidades necessárias a esses profissionais da escrita, para que se possa propor possíveis diretrizes de aperfeiçoamento das condições de ensino oferecidas atualmente pela Área.

Este artigo se propõe a analisar os dados parciais obtidos pela primeira etapa da pesquisa, e possui um caráter exploratório, que busca delimitar o fenômeno estudado.

\section{Método}

Esta pesquisa pode ser considerada exploratória, uma vez que entrevistou pessoas que tiveram um contato prático com o problema em questão. Segundo Gil (2002, p. 41), as pesquisas que têm como objetivo proporcionar "maior familiaridade com o problema, com vistas a torná-lo mais explícito ou a constituir hipóteses", podem ser assim denominadas, uma vez que esse tipo de pesquisa tem como objetivo principal "o aprimoramento de ideias ou a descoberta de intuições".

Para coletar as percepções dos participantes, utilizouse questionário on-line, realizando um censo com os 80 alunos matriculados nos cursos de mestrado e doutorado entre os anos de 2012 a 2016. Desse total, apenas oito optaram por não participar da pesquisa, ou não puderam 
ser localizados. Os participantes foram divididos em 4 grupos de acordo com os critérios da Tabela 1.

Tabela 1. Critério de divisão dos grupos

\begin{tabular}{lc}
\hline \multicolumn{1}{c}{ Grupos } & $\begin{array}{l}\text { Número de } \\
\text { participantes }\end{array}$ \\
\hline $\begin{array}{l}\text { Grupo 1: Mestrado e doutorado cursados } \\
\text { pela primeira vez e em andamento em } \\
\text { Escrita Criativa }\end{array}$ & 32 participantes \\
$\begin{array}{l}\text { Grupo 2: Mestrado concluído em Escrita } \\
\text { Criativa e doutorado em andamento na } \\
\text { mesma área }\end{array}$ & 9 participantes \\
$\begin{array}{l}\text { Grupo 3: Apenas mestrado concluído em } \\
\text { Escrita Criativa } \\
\text { Grupo 4: Doutorado concluído em Escrita } \\
\text { Criativa }\end{array}$ & 28 participantes \\
\hline
\end{tabular}

Os questionários foram concebidos a partir do sistema SurveyMonkey, uma plataforma de geração de questionários on-line, e foram compostos por perguntas fechadas em número de 14 questões para o primeiro grupo, 16 para o segundo, 19 para o terceiro e 16 para o quarto. $\mathrm{O}$ acesso foi dado através de um link enviado por e-mail, que, uma vez acessado, redirecionava os participantes da pesquisa para o ambiente em rede, no qual era possível marcar as respostas e salvar os resultados de maneira anônima.
As questões apresentadas foram divididas em três dimensões que buscavam traçar: 1) o perfil do aluno; 2) a sua trajetória no programa; e 3) os resultados nas práticas de escrita e acadêmica dos egressos.

Para este artigo, apresentamos a análise de duas questões que fazem parte da primeira dimensão, isto é, do perfil do aluno que procura o curso de pós-graduação na Área de Escrita Criativa na PUCRS. Dado o volume de informações obtidas, os demais resultados serão analisados em artigos subsequentes.

A primeira dessas questões, que faz parte da dimensão perfil do aluno, foi aplicada aos quatro grupos estudados e buscou observar os motivos que levaram os participantes a optarem por um mestrado ou doutorado na área de Escrita Criativa (Ver Gráfico 1). A questão foi composta por sete itens avaliados por meio de cinco graus de importância, que variaram de "discordo plenamente" a "concordo plenamente".

Na segunda dessas questões, buscou-se compreender qual a importância atribuída pelos discentes e egressos da área às atividades e práticas que compõem a formação do profissional em Escrita Criativa (Ver Gráfico 2). A questão foi composta por oito itens, numa escala que variou de 1 a 5, entre "nada importante" até "muito importante", e também foi respondida por todos os grupos.

Gráfico 1. Questão A: Média ponderada das respostas

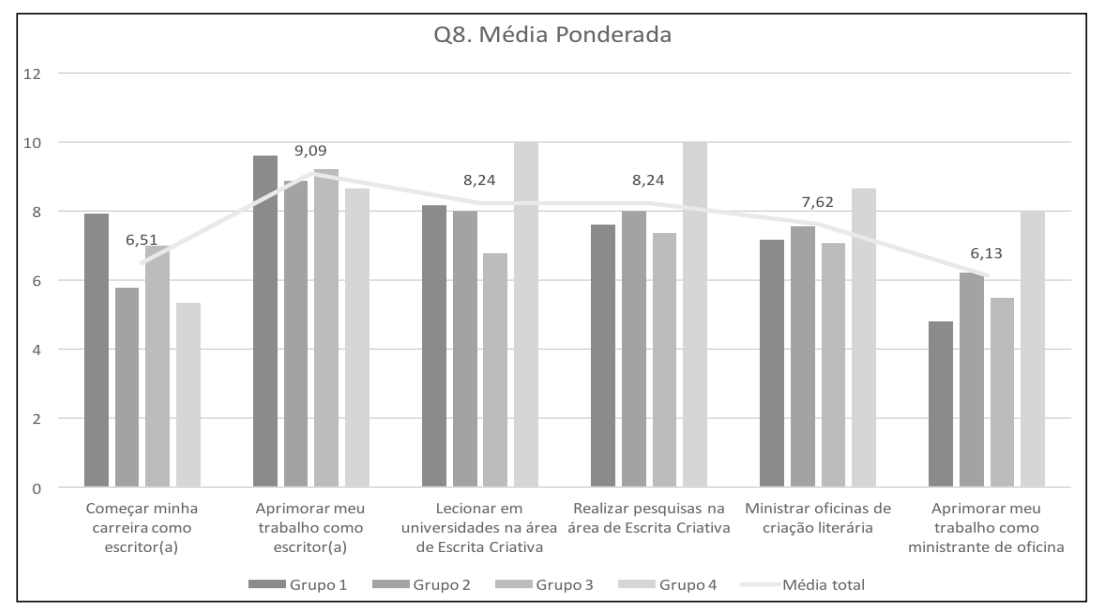

Gráfico 2. Questão B: somente respostas marcadas como "muito importante"

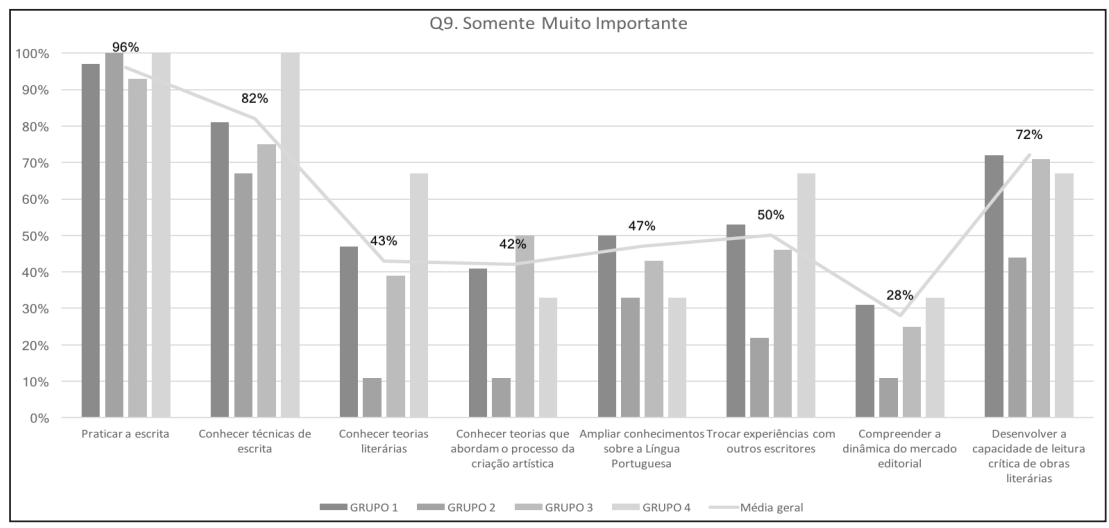




\section{Resultados}

A análise das informações contidas na resposta da Questão A: Quais motivos levaram você a escolher a Escrita Criativa? Tem por objetivo identificar e compreender o perfil dos discentes que procuram a área de Escrita Criativa.

O item "Começar minha carreira como escritor(a)" contou com 24 respostas "concordo parcialmente" $(29,2 \%)$ e 21 "concordo completamente" $(33,3 \%)$, com predominância no Grupo 1 (ingressantes no curso) e Grupo 3 (formados no mestrado que não seguiram o doutorado), de um total de 72 na soma dos grupos. Esse número reduz-se nos grupos 2 (alunos do doutorado que concluíram o mestrado na área) e Grupo 4 (doutorados concluídos), onde aparecem 10 respostas "discordo plenamente" na soma dos grupos e 14 "não concordo, nem discordo". A média ponderada deste item, na escala de 1 a 10, é de 7,94 para o Grupo 1; 5,78 para o Grupo 2; 7 para o Grupo 3 e de 5,34 para o Grupo 4.

Já o item que apresenta maior consonância entre os grupos é "Aprimorar meu trabalho como escritor", no qual 55 participantes concordaram plenamente $(76,4 \%)$ e apenas um entre os quatro grupos discordou plenamente $(1,4 \%)$. A média ponderada desse item, na escala de 1 a 10 , é portanto, bastante próxima em todos os grupos: 9,62 no Grupo 1; 8,88 no Grupo 2; 9,22 no Grupo 3 e 8,66 no Grupo 4.

$\mathrm{O}$ item "Lecionar em universidades" e "Realizar pesquisas na área" estão ligados à atividade acadêmica a que se propõem os programas de pós-graduação stricto sensu, demonstrando nas respostas dos entrevistados um equilíbrio no grau de importância. Na soma dos grupos, 30 entrevistados responderam "concordo plenamente" para o item relativo à docência $(41,2 \%)$, e 27 para o item relativo à pesquisa $(37,5 \%)$. Nesses mesmos itens, 20 participantes concordaram parcialmente em relação à docência $(27,8 \%)$ e 24 à pesquisa $(33,3 \%), 8$ participantes discordaram totalmente do item relativo à pesquisa $(9,7 \%)$, enquanto que 7 entrevistados discordaram totalmente do item relativo à docência $(11,1 \%)$.

$\mathrm{Na}$ soma de todos os grupos, o item "Aprimorar meu trabalho como ministrante de oficina de criação literária" obteve 8 respostas "concordo plenamente" $(11,2 \%)$ e 23 "discordo plenamente" (32\%), enquanto que "Ministrar oficinas de criação literária" obteve 21 respostas $(29,2 \%)$ "concordo plenamente" e 10 respostas "discordo plenamente" (14\%).

Já a análise das informações contidas na resposta da

Questão B: Qual a importância dos seguintes itens na formação do escritor? tem por objetivo compreender a importância das atividades que compõem a formação do profissional em Escrita Criativa.
O item considerado mais importante, em todos os grupos, foi "Praticar a escrita", com 95,8\% das respostas assinaladas como "muito importante". O segundo item na escala de importância foi "Conhecer técnicas de escrita", marcado como "muito importante" em $81,7 \%$ das respostas. Na sequência, o item "Desenvolver a capacidade de leitura crítica de obras literárias", com $72,1 \%$ das respostas como "muito importante". O quarto item elencado foi "Trocar experiências com outros escritores". O item obteve 49,6\% das respostas "muito importante". Em quinto lugar, o item "Ampliar conhecimentos sobre a Língua Portuguesa", que foi considerado "muito importante" para $46,9 \%$ dos participantes da pesquisa.

O item "Conhecer teorias literárias" apresentou $42,7 \%$ das respostas na opção "muito importante", o mesmo número do item "Conhecer teorias que abordam o processo da criação artística". É interessante notar que ambos os itens obtiveram apenas uma resposta "muito importante" entre os integrantes do Grupo 2. As duas questões têm relação com disciplinas teóricas da grade curricular. Por outro lado, $50 \%$ dos integrantes do Grupo 3 avaliaram como "muito importante" o item "Conhecer teorias que abordam o processo da criação artística", a maior média dentre os grupos.

Entre os itens que foram menos associados à resposta "muito importante", destaca-se "Compreender a dinâmica do mercado editorial". Apenas 27,8\% dos participantes consideraram o item "muito importante". $\mathrm{O}$ item foi relativamente o pior avaliado pelos quatro grupos, na medida em que essa importância é atribuída em comparação a outros itens que, no julgamento dos entrevistados, são mais relevantes para a formação do escritor. Ainda assim, 44,4\% dos participantes consideraram o item "importante", totalizando $70,8 \%$ de respostas que atribuem ao item algum nível de importância ("importante" ou "muito importante").

O desempenho dos demais itens associados à resposta "importante", em ordem crescente, foi o seguinte: "Praticar a escrita" (4,2\%); "Conhecer técnicas de escrita" $(20,8 \%)$; "Desenvolver a capacidade crítica das obras literárias" (27,8\%); "Conhecer teorias que abordam o processo de criação artística", "Ampliar conhecimentos sobre a língua portuguesa" e "Trocar experiências com outros escritores" (os três com 45,8\%), e "Conhecer teorias literárias" (50\%).

\section{Discussão dos Resultados}

Os resultados obtidos nesta etapa da pesquisa vão ao encontro de uma compreensão tradicional da área de Escrita Criativa. A prática da escrita, desse modo, é percebida como a atividade mais relevante na formação do escritor e, como tal, deveria estar presente também 
na Academia, ambiente no qual o saber literário é tradicionalmente restrito ao conhecimento da teoria e da história da literatura.

Inserida nas instituições universitárias, a Escrita Criativa explora o potencial inventivo daqueles alunos que procuram o curso de Letras não porque ambicionam uma carreira docente, mas com o intuito de se tornar escritores, de perceber a literatura pelos olhos da criação ${ }^{1}$. Nesse sentido, a pós-graduação em Letras da PUCRS aposta em uma ideia nova - mas nova somente em nosso país, já que obtém resultados expressivos, há várias décadas, no exterior.

A ênfase na prática da escrita relaciona-se ainda com a análise das outras duas atividades consideradas pelos alunos como mais importantes para a formação do escritor, quais sejam: "conhecer as técnicas de escrita" (referida por $82 \%$ dos alunos) e "desenvolver a capacidade de leitura crítica de obras literárias (referida por $72 \%$ dos alunos).

No que diz respeito à técnica da escrita, Cecília Almeida Salles corrobora a noção de que os escritores, mesmos aqueles não inseridos no contexto formal de uma oficina ou de um curso de pós-graduação na área da Escrita Criativa, valem-se do seu estudo para atuar como um relojoeiro do ofício criativo: desmontando o relógio para compreender o seu funcionamento.

Os processos mostram, muitas vezes, a prática dessas técnicas. Na música, teatro e dança, a necessidade de exercitar técnicas tem seu momento específico no itinerário criador. As diferentes linguagens mostram essa questão da prática de modos diversos: assim como um bailarino "faz aulas", escritores contam dos filmes que assistiram ou dos livros que leram tentando "desmontar ou descosturar os fios narrativos e compreender os modos de narrar" (SALLES, 2001, p. 111-112).

Esse entendimento também é confirmado por Paul Dawson, em seu livro Creative Writing and the New Humanities, que analisa a trajetória e o lugar da Escrita Criativa na universidade norte-americana, inglesa e australiana. Tendo como base uma análise histórica da pedagogia da leitura em oficinas literárias, Dawson afirma que a melhor maneira de aprender a arte da escrita é por meio da leitura, por isso o que possibilita uma oficina de Escrita Criativa funcionar é antes uma teoria da leitura, e não uma teoria da escrita. Nesse sentido, o pesquisador australiano aponta para a necessidade de se estabelecer um método de ensino de leitura crítica nos cursos de Escrita Criativa, direcionado não só para apreciação da obra literária, mas também para o aperfeiçoamento técnico da arte de escrever:

\footnotetext{
Sobre este assunto, ver ASSIS BRASIL, 2015, p. 03.
}

O melhor jeito de aprender a escrever, de acordo com a maioria dos professores de Escrita Criativa, é lendo. Em Creative Writing in America: Theory and Pedagogy, [...] o editor, Joseph Moexley, aponta que a 'necessidade dos escritores serem leitores ativos é recomendada mais que qualquer outra coisa' pela maioria dos contribuidores. No livro The Writing Book de Kate Grenville, um best-seller sobre escrita que serve de texto básico para muitos programas de escrita australianos, o ponto final é que 'quanto mais você lê, melhor escreve.'-Há de haver algo mais quando se trata de Escrita Criativa, entretanto, ou a área não seria nada mais que um clube do livro institucionalizado. Deve haver um método particular de leitura que é ensinado. E há. Estudantes de Escrita Criativa são estimulados a ler não apenas por apreciação literária, mas para ajudar na sua escrita. É isso que entendemos pela expressão ler como um escritor, ler com o objetivo de descobrir maneiras de aprimorar a escrita (DAWSON, 2005, p. $90-91)^{2}$.

Dessa maneira, a capacidade de leitura crítica de obras literárias está ligada a uma percepção ativa da leitura. Como afirma Bettega (2012, p. 21), é uma ideia muito próxima do conceito proustiano de uma leitura na qual, quando a findamos, "continuamos a gozar do poder intelectual que temos na solidão (...), continuamos a poder ser inspirados, continuamos em pleno trabalho fecundo do espírito". Ou seja: lemos para escrever e aplicar na escrita aquilo que aprendemos lendo.

Esse viés ativo e prático, presente em grande parte das respostas dos entrevistados, revela-se ainda ao observarmos os itens com menor importância relativa nas questões A e B.

Se, por um lado, "Aprimorar meu trabalho como escritor(a)" obteve alto índice de respostas para a pergunta "Quais motivos levaram você a escolher o curso de Escrita Criativa?", "Começar minha carreira como escritor(a)" obteve índice baixo, o que parece indicar que os entrevistados já se consideram escritores com algum domínio da escrita, procurando o curso para o seu aperfeiçoamento por meio do exercício contínuo e qualificado.

\footnotetext{
Tradução nossa. No original: "The best way to learn how to write, according to most teachers of Creative Writing, is to read. In Creative Writing in America: Theory and Pedagogy, [...] the editor, Joseph Moexley, points out that the "need for writers to be active readers is stressed more than any other recommendation' by the majority of the contributors. In Kate Grenville's The Writing Book, a bestselling handbook which has served as a textbook in many Australian writing programmes, the final point is that 'the more you read, the better you'll write'. There must be more than this to Creative Writing, however, or it would be no more than an institutionalised book club. There must be a particular method of reading which is taught. And there is. Students of Creative Writing are encouraged to read not merely for literary appreciation, but in order to aid their writing. This is what we understand by the term reading as a writer; reading with the aim of discovering ways to improve one's own writing."
} 
Numa lógica inversa, a intenção de "Ministrar oficinas de criação literária" obteve índice maior do que "Aprimorar meu trabalho como ministrante de oficina", indicando que os entrevistados se consideram escritores, mas ainda não se sentem preparados para ministrar oficinas literárias, procurando o curso para tal preparação.

Outro dado que merece destaque pela pouca importância relativa atribuída é o item "Compreender a dinâmica do mercado editorial". A relevância tímida desse item vai ao encontro de certas práticas observadas em programas de Escrita Criativa no exterior. $\mathrm{Na}$ Universidade de East Anglia, por exemplo, não são oferecidas disciplinas específicas acerca do mercado editorial, e a discussão sobre os meandros da publicação e as vicissitudes da carreira literária se dão por meio de eventos periódicos com agentes literários e editores.

A análise desses dados com menor importância relativa nos permite formular o raciocínio de que as preocupações dos alunos que se candidatam ao curso se centram predominantemente na última etapa do processo de criação, ou seja, o ato criativo propriamente dito. Neste contexto, as preocupações exteriores, como as questões de mercado ou da teoria (historicamente ligada à instância da crítica literária) ficam em segundo plano.

Não obstante, a relevância das competências teóricas parece aumentar para os entrevistados em proporção direta ao nível de formação destes, já que respostas relacionadas a elas são predominantes entre o Grupo 4, mas de maneira mais discreta nos outros grupos (respostas como "Lecionar em universidades na área de Escrita Criativa" e "Realizar pesquisas na área de Escrita Criativa" - para a questão A - e "Conhecer teorias literárias" - para a questão B).

Ressalvada a discrepância entre o número de participantes entre grupos aqui examinados, essa tendência parece obedecer a um movimento coerente se encararmos algumas das perspectivas acadêmicas que se abrem para um profissional em Letras na área de Escrita Criativa, tais como a prática da pesquisa ou o ingresso na docência de nível superior. Também é possível entender que essa maior importância atribuída aos estudos literários por esse grupo esteja relacionada a uma tomada de consciência do papel das teorias no processo de escrita, como descreve Ramey:

Para muitos escritores abertos a tais possibilidades, o aparato filosófico, social, histórico, cultural e psicológico da teoria crítica ajuda a descobrir seus objetivos e propósitos literários, enquanto também permite que reconheçam antecedentes, conexões e métodos que podem gerar novas ideias e práticas que beneficiam sua escrita profundamente. A teoria crítica permite que escritores aprendam não apenas seguindo orientações teóricas externas, mas também buscando princípios que serão usados seletivamente e cuidadosamente como guias para revelar os valores que são importantes para eles como indivíduos e membros de uma comunidade, formando uma consciência maior de seu público e práticas de leitura (RAMEY, 2007, p.46) ${ }^{3}$.

Essas hipóteses, no entanto, devem ser vistas com ressalvas devido ao caráter genérico atribuído à teoria literária nas questões formuladas nesta pesquisa, e, também, à complexidade da questão. O que se procurou nesta etapa foi atingir uma visão preliminar da relevância dos aspectos teóricos que influenciam a formação do profissional em Escrita Criativa. É possível pensar que, uma vez aprofundada a discussão, os resultados obtidos apresentem variações, principalmente no que diz respeito à relevância atribuída a determinado campo teórico em detrimento de outro, inclusive de teorias que trabalham a criação artística e a criatividade em geral, considerando a tensão e o diálogo existentes entre a Escrita Criativa e os estudos literários se revelam não só no terreno institucional, mas também nos trabalhos acadêmico dos discentes. Essa é uma relação instável, em permanente estado de questionamento e elaboração - e não só na realidade brasileira. São tentativas de negociação, que, segundo Dawson (2005, p. 161), devem procurar "manter o objetivo pedagógico central da Escrita Criativa, que é ensinar os estudantes a desenvolverem suas técnicas de escrita para que possam produzir trabalhos literários".

Esse debate é vivenciado pelos discentes e docentes da PUCRS, tanto no nível da estrutura do Programa de Pós-Graduação quanto nas dissertações e teses defendidas, e apresentam-se como um desafio e uma oportunidade de construção de um diálogo produtivo entre as áreas de especialização dos cursos de pós-graduação em Letras, dentro do contexto das novas humanidades. É um tema, pois, que exige reflexão aprofundada devido à sua importância no cotidiano e na consolidação da Área de Escrita Criativa na universidade brasileira.

\section{Conclusão}

Esta pesquisa, ainda que tenha carácter parcial e exploratório, constitui-se como documento pioneiro em nosso país, pois é executada no âmbito de uma experiência

\footnotetext{
Tradução nossa. No original: "For many creative writers who are open to such possibilities, the philosophical, social, historical, cultural and psychological apparatus of critical theory has helped them discover their central literary purposes and goals, whilst also enabling them to recognize antecedents, connections and methods that can powerfully generate new ideas and practices for the benefit of their writing. Critical theory enables writers to learn to write not by following prescribed external critical dictates, but by seeking principles to use selectively and thoughtfully as a guide to reveal the values that are important to them as individuals and members of a community, partly by forming a more precise awareness of audiences and reading practices."
} 
única, desenvolvida pela Pontifícia Universidade Católica do Rio Grande do Sul. Os dados das demais questões ainda estão sendo tabulados e merecerão um segundo tratamento, quando ampliaremos as diversas possibilidades que se apresentam no trato de material tão profícuo.

O que fica evidente, porém, é o grande interesse pelos cursos de mestrado e doutorado em Escrita Criativa, e o empenho de discentes e docentes em aperfeiçoá-los, para que alunos egressos possam qualificar melhor suas formações acadêmicas a fim de enquadrar-se com melhor apuro teórico e técnico no período posterior às respectivas conclusões.

\section{Referências}

ASSIS BRASIL, Luiz Antonio. Escrita criativa - e reflexiva, ma non tropo. Scriptorium, Porto Alegre, v. 1 n. 1, p. 1-5. jul.-dez. 2015.

BETTEGA, Amilcar. Da leitura à escrita: a construção de um texto, a formação de um escritor. 2012. 310 f. Tese (Doutorado em Letras) - Pontifícia Universidade Católica do Rio Grande do Sul; Université Sorbonne Nouvelle, Porto Alegre; Paris.
CREATIVE WRITING. University of East Anglia: School of Literature, Drama and Creative Writing. Disponível em: $<$ https://www.uea.ac.uk/literature/creative-writing $>$. Acesso em: 02 jan. 2017.

DAWSON, Paul. Creative writing and the new humanities. Abington: Routledge, 2005.

GIL, Antônio Carlos. Como elaborar projetos de pesquisa. 4. ed. São Paulo: Atlas, 2002.

HARPER, Graeme. The future for creative writing. Chichester/ Malden: Wiley-Blackwell, 2014.

RAMEY, Lauri. Creative Writing and Critical Theory In: EARNSHAW, Steven. The Hand Book of Creative Writing. Edinburgh Edinburgh: University Press, 2007.

SÁBATO, Ernesto. O escritor e seus fantasmas. São Paulo: Companhia das Letras, 2003.

SALLES, Cecilia Almeida. Gesto inacabado: processo de criação artística. 5. ed. rev. e ampl. São Paulo: Intermeios, 2001.

WRITING. Columbia University: School of the Arts Writing Program. Disponível em: <http://arts.columbia.edu/writing>. Acesso em: 02 jan. 2017.

Recebido: 29 de maio de 2017

Aprovado: 26 de junho de 2017

Contato: laab@portoweb.com.br

(Luiz Antonio de Assis Brasil) 